\title{
Ganglions of the hand and wrist: Retrospective statistical analysis of 520 cases
}

\author{
Sebastian Kuliński ${ }^{1, ~ B-D, ~ F, ~ O l g a ~ G u t k o w s k a 1, ~ B, ~ C, ~ E, ~ F, ~ S y l w i a ~ M i z i a 2, ~ C, ~ F, ~ J e r z y ~ G o s k ~}{ }^{1, A, C, E, F}$ \\ 1 Department of Traumatology, Clinic of Traumatology and Hand Surgery, Wroclaw Medical University, Poland \\ ${ }^{2}$ Department of Public Health, Department of Organization and Management, Faculty of Health Science, Wroclaw Medical University, Poland \\ A - research concept and design; $\mathrm{B}$ - collection and/or assembly of data; C - data analysis and interpretation; \\ $D$ - writing the article; $E$ - critical revision of the article; $F$ - final approval of article
}

\section{Address for correspondence}

Jerzy Gosk

E-mail:kcu.umedwroc@gmail.com

\section{Funding sources}

none declared

\section{Conflict of interest}

none declared

\section{Acknowledgments}

We would like to thank Bartosz Witkowski for providing medical writing services on behalf of Wroclaw Medical University

Received on February 8, 2016

Revised on July 16, 2016

Accepted on September 6, 2016

\section{Abstract}

Background. Ganglions constitute the most common tumor type of the hand and wrist region. They have a non-neoplastic character and affect patients of all ages.

Objectives. The purpose of this work was to analyze the epidemiological data of a representative group of patients diagnosed with ganglions of the hand and wrist.

Material and methods. Five-hundred-and-twenty patients operated on for ganglions of the hand and wrist between the years 2000 and 2014 were included in the study. For the statistical analysis, STATISTICA v. 10 was used. Categorical data was analyzed using the $x^{2}$. The distribution of two and more independent samples was compared through the Mann-Whitney U test and Kruskal-Wallis test followed by pairwise comparisons for significant test statistics, respectively.

Results. In the studied group of patients, ganglions affected females more often than males, with a 2.8:1 ratio. No statistically significant differences in age distribution between women and men (median age 38 vs. 40 years) were found. Ganglions affected both sides of the body with comparable equality. Wrist ganglions predominated (76\%). The patients diagnosed with hand ganglions were statistically significantly older $(p<0.001)$, and the right hand was affected more often ( $p=0.003)$. A statistically significant difference in age distribution between the patients with DWG (dorsal wrist ganglions) and VRG (volar retinacular ganglions) was observed $(p<0.001)$. DWG affected the left side $(p=0.003)$ and VRG the right side $(p=0.005)$ of the body more often.

Conclusions. Statistical analysis of our patients confirmed much of the previously published data. Although the diagnosis and treatment of ganglions of the hand and wrist are relatively uncomplicated, the pathophysiology of their formation is still waiting to be thoroughly explained.

Key words: tumor, wrist, ganglion cyst, hand, surgical procedure

DOI

$10.17219 /$ acem $/ 65070$

\section{Copyright}

Copyright by Author(s)

This is an article distributed under the terms of the

Creative Commons Attribution Non-Commercial License

(http://creativecommons.org/licenses/by-nc-nd/4.0/) 
Ganglions constitute the most common tumor type found in the hand and wrist region. ${ }^{1-3}$ They have a nonneoplastic character and usually manifest as solitary, typically located tumors. ${ }^{3}$ Ganglions are found in patients of all ages, with peak incidence in the $2^{\text {nd }}-4^{\text {th }}$ decade of life. ${ }^{1,4}$ A significantly higher incidence in women is typical. ${ }^{1,2}$ The above-cited epidemiological data is derived from studies conducted in the past decades. ${ }^{1,2,4}$

The aim of this work is to describe a large clinical population of patients operated on for ganglions of the hand and wrist at our institution over a 15 -year period. Study design: retrospective case series.

\section{Material and methods}

The study group was comprised of 519 patients treated between 2000 and 2014, in whom a total of 523 ganglions of the hand and wrist had been removed. Four patients had multiple lesions, three of whom had the ganglions removed during a single procedure: a 20-year-old female had 2 volar retinacular ganglions resected from her left ring finger, a 25 -year-old male had 2 dorsal wrist ganglions located on the radial and ulnar sides of his left wrist excised and a 67-year-old female patient had 2 ganglions arising from the extensor tendon sheath of either hand removed. A 37-year-old female had a dorsal wrist ganglion removed from her left wrist and after a month she had a volar retinacular ganglion resected from her right middle finger. Since the patient had been operated on twice within a pronounced time interval, the ganglions were located on both sides of the body and their location was different on either side (middle finger, wrist), the total number of patients for the needs of statistical analysis was calculated to be 520 .

The data analysis consisted of:

- evaluation of the most common ganglion locations within the hand and wrist region;

- comparison of patients diagnosed with wrist ganglions with those having ganglions of the hand (percentage, gender, age, side of the body);

- assessment of any existing relationship between ganglion location and patient gender;

- assessment of any existing relationship between ganglion location and patient age;

- assessment of any existing relationship between ganglion location and the side of the body.

For the statistical analysis, STATISTICA v. 10 was used. Categorical data was analyzed using the $\chi^{2}$. The distribution of two and more than two independent samples was compared through the Mann-Whitney $U$ test and Kruskal-Wallis test followed by pairwise comparisons for significant test statistics, respectively. The likelihood of committing a type one error was set to 0.05 .

This research received approval from the local Bioethics Committee and from the institution at which it was carried out. All procedures performed in this study were in accordance with the 1964 Helsinki Declaration and its later amendments.

\section{Results}

The results of the analysis are presented in Tables 1-7 and summarized below.

Out of 520 patients included in the study, 136 (26\%) were males and 384 (74\%) were females. The mean age of the patients was 41.3 years, the median age was 39.5 and the age range was $2-83$ years (Table 1 ). The lesions were located on both sides of the body with comparable equality (the right side $-49 \%$, the left side $-51 \%$ ). Wrist ganglions predominated (76\%) and were located more often on the dorsal aspect of the wrist than on the volar aspect (55\% and $21 \%$, respectively). Volar retinacular ganglions constituted the most numerous group of the hand ganglions, accounting for $20.6 \%$ of the total number of the lesions (Table 1). Almost half (47\%) of all the ganglions arising from the tendon sheath were located within the middle finger. There was no statistically significant differ-

Table 1. Clinical characteristics of patients treated for ganglions ( $X$ - mean; SD - standard deviation)

\begin{tabular}{|c|c|c|}
\hline Gender, n (\%) & $\begin{array}{l}\text { female } \\
\text { male }\end{array}$ & $\begin{array}{l}384(74) \\
136(26)\end{array}$ \\
\hline Age (years) & $\begin{array}{c}\mathrm{X} \pm \mathrm{SD} \\
\text { median (range) }\end{array}$ & $\begin{array}{l}41.3 \pm 16.9 \\
39.5(2-83)\end{array}$ \\
\hline Side, n (\%) & $\begin{array}{l}\text { right } \\
\text { left } \\
\text { both }\end{array}$ & $\begin{array}{c}253(48.7) \\
266(51.1) \\
1(0.2)\end{array}$ \\
\hline Location, n (\%) & $\begin{array}{l}\text { hand } \\
\text { wrist }\end{array}$ & $\begin{array}{l}126(24) \\
394(76)\end{array}$ \\
\hline Location, n (\%) & $\begin{array}{l}\mathrm{DWG}^{1} \\
\mathrm{VWG}^{2} \\
\mathrm{VRG}^{3} \\
\mathrm{EXT}^{4} \\
\mathrm{DIP}^{5} \\
\mathrm{PIP}^{6} \\
\mathrm{CMB}^{7}\end{array}$ & $\begin{array}{c}285(54.8) \\
109(21.0) \\
107(20.6) \\
12(2.3) \\
3(0.5) \\
2(0.4) \\
2(0.4)\end{array}$ \\
\hline
\end{tabular}

dorsal wrist ganglions; ${ }^{2}$ volar wrist ganglions; ${ }^{3}$ volar retinacular ganglions; ${ }^{4}$ extensor tendon ganglions; ${ }^{5}$ distal interphalangeal joint ganglions;

${ }^{6}$ proximal interphalangeal joint ganglions; ${ }^{7}$ carpometacarpal boss.

Table 2. Clinical characteristics of the patients with respect to gender

\begin{tabular}{|lcccc|c|}
\hline Gender & & Female & Male & $p$ \\
\hline Number, $n$ & & 384 & 136 & \\
Age (years) & $X \pm S D$ & $41.2 \pm 17.0$ & $41.6 \pm 16.7$ & $0.731^{*}$ \\
& median (range) & $38(10-83)$ & $40(2-83)$ & \\
Side, $n(\%)$ & right & $186(48.4)$ & $67(49.3)$ & $0.829^{* *}$ \\
& left & $197(51.3)$ & $69(50.7)$ & \\
& both & $1(0.3)$ & $0(0)$ & \\
\hline
\end{tabular}

$X$ - mean; SD - standard deviation; * Mann-Whitney $U$ test; ** $\chi^{2}$ test. 
Table 3. Clinical characteristics of the patients with respect to ganglion location (X-mean; SD - standard deviation; ${ }^{*} \chi^{2}$ test; ${ }^{* *}$ Mann-Whitney $U$ test; ${ }^{* * *} \chi^{2}$ test - the case, in which two ganglions of both hands were treated has been excluded from the analysis)

\begin{tabular}{|c|c|c|c|c|}
\hline Location & & Hand & Wrist & $p$ \\
\hline Number, n & & 126 & 394 & \\
\hline Gender, n (\%) & $\begin{array}{l}\text { female } \\
\text { male }\end{array}$ & $\begin{array}{l}95(75.4) \\
31(24.6)\end{array}$ & $\begin{array}{l}289(73.4) \\
105(26.6)\end{array}$ & $0.649^{*}$ \\
\hline Age (years) & $\begin{array}{c}\mathrm{X} \pm \mathrm{SD} \\
\text { median (range) }\end{array}$ & $\begin{array}{l}47.7 \pm 17.6 \\
50.5(2-83)\end{array}$ & $\begin{array}{l}39.2 \pm 16.2 \\
37(10-83)\end{array}$ & $<0.001^{* *}$ \\
\hline Side, n (\%) & $\begin{array}{l}\text { right } \\
\text { left } \\
\text { both }\end{array}$ & $\begin{array}{c}75(59.5) \\
50(39.7) \\
1(0.8)\end{array}$ & $\begin{array}{c}178(45.2) \\
216(54.8) \\
-\end{array}$ & $\begin{array}{c}0.003^{* * *} \\
-\end{array}$ \\
\hline
\end{tabular}

Table 4. Distribution of ganglion location with respect to patient gender $\left({ }^{*} \chi^{2}\right.$ test $)$

\begin{tabular}{|c|c|c|c|c|}
\hline \multicolumn{2}{|l|}{ Gender } & Female & Male & $p^{*}$ \\
\hline $\begin{array}{l}\text { Location, } \\
\mathrm{n}(\%)\end{array}$ & $\begin{array}{l}\text { DWG }^{1} \\
V^{2} G^{2} \\
V^{2} G^{3} \\
E^{4} T^{4} \\
\text { DIP }^{5} \\
\text { PIP }^{6} \\
\text { CMB }^{7}\end{array}$ & $\begin{array}{c}212(55.2) \\
77(20.1) \\
80(20.8) \\
9(2.4) \\
2(0.5) \\
2(0.5) \\
2(0.5)\end{array}$ & $\begin{array}{c}73(53.7) \\
32(23.5) \\
27(19.9) \\
3(2.2) \\
1(0.7) \\
0(0) \\
0(0)\end{array}$ & 0.903 \\
\hline Total & & 384 & 136 & - \\
\hline Gender & & female & male & $p^{*}$ \\
\hline $\begin{array}{l}\text { Location, } \\
\text { n (\%) }\end{array}$ & 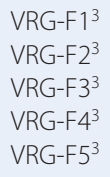 & $\begin{array}{c}7(8.7) \\
18(22.5) \\
37(46.3) \\
11(13.8) \\
7(8.7)\end{array}$ & $\begin{array}{c}3(11.1) \\
4(14.8) \\
13(48.2) \\
1(3.7) \\
6(22.2)\end{array}$ & 0.236 \\
\hline Total & & 80 & 27 & - \\
\hline
\end{tabular}

${ }^{1}$ dorsal wrist ganglions; ${ }^{2}$ volar wrist ganglions; ${ }^{3}$ volar retinacular ganglions (F1 - thumb, F2 - index finger, F3 - middle finger, F4 - ring finger, F5 - little finger); ${ }^{4}$ extensor tendon ganglions; ${ }^{5}$ distal interphalangeal joint ganglions; ${ }^{6}$ proximal interphalangeal joint ganglions; ${ }^{7}$ carpometacarpal boss.

Table 5. Distribution of patient age with respect to ganglion location

\begin{tabular}{|c|c|c|c|c|}
\hline \multirow[b]{2}{*}{ Location } & \multirow[b]{2}{*}{$\begin{array}{c}\text { Number } \\
n\end{array}$} & \multicolumn{2}{|c|}{ Age (years) } & \multirow[b]{2}{*}{$\mathrm{p}^{*}$} \\
\hline & & $\mathrm{X} \pm \mathrm{SD}$ & $\begin{array}{l}\text { Median } \\
\text { (range) }\end{array}$ & \\
\hline $\mathrm{DWG}^{1}$ & 285 & $38.5 \pm 17.3$ & $35(10-83)^{A}$ & \multirow[t]{7}{*}{$<0.001$} \\
\hline $\mathrm{WWG}^{2}$ & 109 & $41.2 \pm 12.5$ & 39 (19-68) & \\
\hline $\mathrm{VRG}^{3}$ & 107 & $47.6 \pm 17.6$ & $51(2-83)^{A}$ & \\
\hline $\mathrm{EXT}^{4}$ & 12 & $45.5 \pm 19.8$ & $36(23-73)$ & \\
\hline $\mathrm{DIP}^{5}$ & 3 & $64.7 \pm 9.2$ & $70(54-70)$ & \\
\hline PIP6 & 2 & $54.5 \pm 6.4$ & $54.5(50-59)$ & \\
\hline $\mathrm{CMB}^{7}$ & 2 & $37.5 \pm 10.6$ & $37.5(30-45)$ & \\
\hline Total & 520 & $41.3 \pm 16.9$ & $39.5(2-83)$ & - \\
\hline
\end{tabular}

${ }^{1}$ dorsal wrist ganglions; ${ }^{2}$ volar wrist ganglions; ${ }^{3}$ volar retinacular ganglions; ${ }^{4}$ extensor tendon ganglions; ${ }^{5}$ distal interphalangeal joint ganglions; ${ }^{6}$ proximal interphalangeal joint ganglions; ${ }^{7}$ carpometacarpal boss; ${ }^{\mathrm{A}} \mathrm{p}<0.05$ for post-hoc comparisons; X-mean; SD - standard deviation; *Kruskal-Wallis test.

ence in age distribution between the groups of female and male patients (median age: 38 vs. 40 years, respectively; Mann-Whitney U test, $\mathrm{p}=0.731$ ) (Table 2).
Table 6. Distribution of the body side with respect to ganglion location

\begin{tabular}{|l|c|c|c|}
\multirow{2}{*}{ Location } & \multicolumn{2}{|c|}{ Side } & \multirow{2}{*}{$\mathrm{p}^{*}$} \\
\cline { 2 - 3 } & right, $\mathrm{n}(\%)$ & left, $\mathrm{n}(\%)$ & 0.02 \\
DWG & $122(48.2)$ & $163(61.3)$ & \\
VWG $^{2}$ & $56(22.1)$ & $53(19.9)$ & \\
VRG $^{3}$ & $65(25.7)$ & $42(15.8)$ & \\
EXT $^{4}$ & $6(2.4)$ & $5(1.9)$ & \\
DIP5 $^{5}$ & $2(0.8)$ & $1(0.4)$ & \\
PIP6 & $2(0.8)$ & $0(0)$ & - \\
CMB $^{7}$ & $0(0)$ & $2(0.7)$ & \\
Total & 253 & 266 & \\
\hline
\end{tabular}

dorsal wrist ganglions; ${ }^{2}$ volar wrist ganglions; ${ }^{3}$ volar retinacular ganglions; ${ }^{4}$ extensor tendon ganglions; ${ }^{5}$ distal interphalangeal joint ganglions; ${ }^{6}$ proximal interphalangeal joint ganglions; ${ }^{7}$ carpometacarpal boss; ${ }^{*} \chi^{2}$ test.

Comparison of the patients treated for ganglions located in the hand and in the wrist revealed a higher age of the former that reached statistical significance (median age: 50.5 vs. 37 years, respectively; Mann-Whitney U test, $\mathrm{p}<0.001$ ) (Table 3). Moreover, the lesions were found more often in the right hand (59.5\%) and the left wrist $(54.8 \%)$, with statistical significance $\left(\chi^{2}\right.$ test, $\left.\mathrm{p}=0.003\right)$ (Table 3). No statistically significant difference between females and males was determined with respect to the occurrence of ganglions in particular locations $\left(\chi^{2}\right.$ test, $\mathrm{p}=0.903$ ) (Table 4).

Analysis of patient age with relation to ganglion location revealed a statistically significant difference in its distribution (Kruskal-Wallis test, $\mathrm{p}<0.001$ ) (Table 5). Posthoc analysis showed a statistically significant difference in age distribution between the patients with dorsal wrist ganglions and those diagnosed with volar retinacular ganglions $(\mathrm{p}<0.001)$ (Table 5$)$. No statistically significant difference in age distribution between the subgroups of patients in whom volar retinacular ganglions were located in particular fingers of the hand was detected $(\mathrm{p}=0.166)$.

Analysis of the ganglion location revealed a statistically significant difference in their distribution between the right and left sides of the body $\left(\chi^{2}\right.$ test, $\mathrm{p}=0.02$ ) (Table 6). Dorsal wrist ganglions were located more often on the left side of the body, with statistical significance $(48.2 \%$ 
vs. $61.3 \% ; \chi^{2}$ test, $\left.\mathrm{p}=0.003\right)$. Volar retinacular ganglions were found more frequently on the right side of the body ( $25.7 \%$ vs. $15.8 \%$; $\chi^{2}$ test, $\left.\mathrm{p}=0.005\right)$. Analysis of the ganglions in the remaining locations showed no statistically significant difference in their laterality.

\section{Discussion}

The statistical analysis of the patients included in our study confirmed many of the previously published data. Ganglions occurred much more often in women than in men, with a ratio of $2.8: 1$. In the article published by Stephen et al., this ratio was $3.1: 1$, in the material presented by Aydin et al. it was $3: 1$ and in the patient group studied by Abe et al. it was $2.6: 1 .^{5-7}$ A lower female : male ratio was reported by Gang and Makhlouf in their article, where in an African population it was $1.5: 1 .^{8}$ Singhal et al. observed a female : male ratio of $1: 1$. The authors concluded, "in India the number of women seeking treatment for elective procedures is quite low due to poverty and ignorance". ${ }^{9}$ However, in most of the recent publications, a higher incidence of ganglions of the hand and wrist in women is clearly noticeable. ${ }^{10-18}$ Although this is a well-known fact, no rational grounds for explaining it are available. According to Rollins et al., female patients are also more predisposed to ganglion recurrence. ${ }^{19}$

The incidence of ganglions is 43 per 100,000 in women and 25 per 100,000 in men and, according to some authors, a further upward trend is observed - 55 per 100,000 of the population per year. ${ }^{3,12,14}$

The mean age of the patients included in our study was $41.3 \pm 16.9$ years and the median age was 39.5 years. These numbers were undoubtedly influenced by the fact that mainly adult patients are admitted to our ward and pediatric patients only sporadically. However, it is worth noticing that more than 220 of our patients (above 42\%) were aged between 20 and 40 years (Fig. 1). Dermon et al. reported an even higher percentage of subjects in this age group (56.5\%). In their study of 119 patients operated on for wrist ganglions, the mean age was 37.2 years (range 14-89.5 years). ${ }^{10}$ The mean age of 26 patients treated operatively for dorsal wrist ganglions in the study by Singhal et al. was 24 years (range $9-55$ years). The ganglions were most common in the patients aged between 15 and 25 years $(46.2 \%)$ and between 25 and 35 years (30.8\%). ${ }^{9}$ The mean age of 40 patients treated surgically for volar wrist ganglions by Aydin et al. was 32.5 years (range 18-65 years). ${ }^{6}$ The age of the patients subjected to ultrasonography of ganglions of the hand and wrist by Teefey et al. ranged from 8 to 66 years (mean age 36.4 years). ${ }^{16}$ The mean age of 24 patients operated on for volar retinacular ganglions by Jebson et al. was 43 years (range 21-68 years). ${ }^{17}$ In another large study of 286 cases treated with one of the following three methods: observation, aspiration or surgical excision, the mean patient age was 35.6 years. ${ }^{15}$ The age of 41 patients treated with arthroscopy for dorsal wrist ganglions by Rizzo et al. ranged from 11 to 56 years (mean age 29.8 years). ${ }^{11}$ The data extracted from the literature and analysis of our own clinical material allow the conclusion that ganglions are a problem affecting mainly young and middle-aged adults. The analysis of our patients revealed no statistically significant differences in age distribution in the groups of female and male patients. This is consistent with the findings by Lidder et al. The authors, having analyzed 117 cases treated operatively for volar retinacular ganglions (77 cases) and dorsal wrist ganglions (40 cases), calculated the mean age in their 83 female patients to be 41.9 years (range 10.488.7 years) and in 34 male patients to be 40.6 years (range 9.2-85.7 years). ${ }^{14}$

In clinical practice, ganglions manifest almost solely as solitary (although sometimes multilocular) tumors, and multiple lesions located in one or more areas of the body are rare. ${ }^{3}$ Dermon et al. removed a total number of 124 wrist ganglions in 119 patients, out of which dorsal wrist

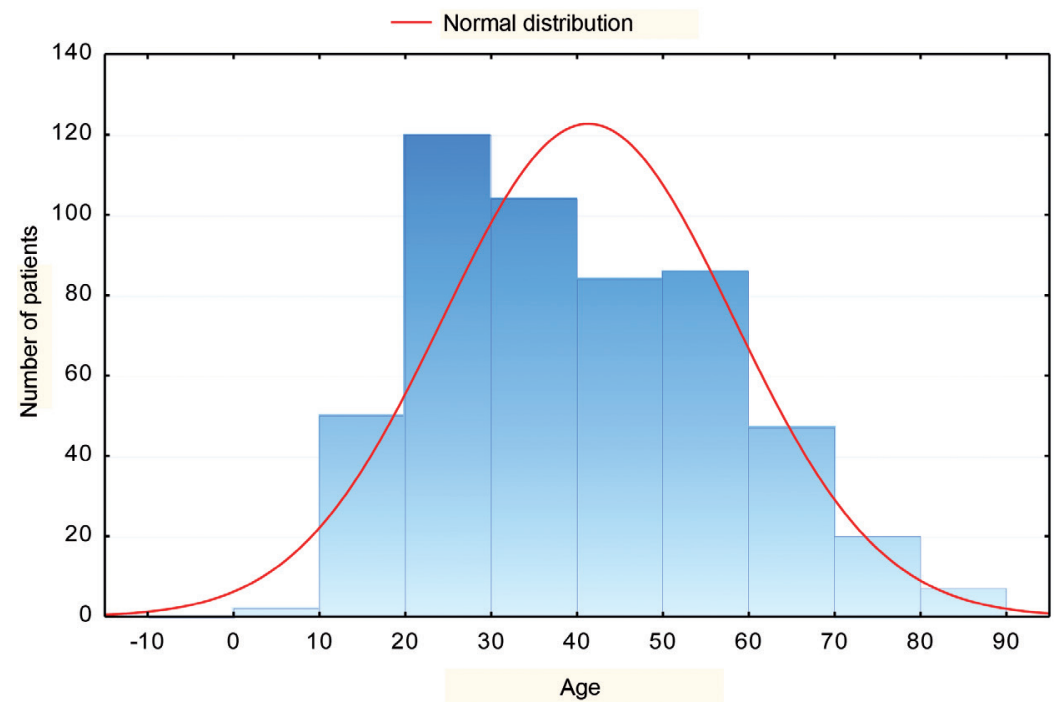

Fig. 1. Histogram presents the age distribution of patients suffering from ganglions 
ganglions constituted $76 \% .^{10}$ In their ultrasonographic study, Teefey et al. diagnosed 60 ganglions of the hand and wrist in 55 patients. ${ }^{16}$ Jebson et al. resected 25 volar retinacular ganglions in 24 patients, ${ }^{17}$ while Abe et al. observed 139 such ganglions in 128 patients. ${ }^{7}$ In our material, in 516 operatively treated patients, ganglions manifested as solitary lesions. Many other authors described only cases of solitary ganglions. ${ }^{6,9,18-20}$

It is generally acknowledged that ganglions of the hand and wrist do not tend to affect one body side more frequently than the other. ${ }^{9,12}$ Our study confirms this observation (R/L: 49/51\%) for both male and female patients ( $\chi^{2}$ test, $\mathrm{p}=0.829$ ).

However, a detailed analysis of the gathered material revealed that ganglions were found more often in the right hand $(59.5 \%)$ and the left wrist (54.8\%), with statistical significance ( $\chi^{2}$ test, $\mathrm{p}=0.003$ ).

Further analysis of ganglion location demonstrated that dorsal wrist ganglions affected the left side of the body more frequently, with statistical significance (61.3 vs. $48.2 \% ; \chi^{2}$ test, $\mathrm{p}=0.003$ ), while volar retinacular ganglions were found more often on the right side of the body (25.7\% vs. $15.8 \%$; $\chi^{2}$ test, $\left.\mathrm{p}=0.005\right)$.

This is in agreement with the previous observation, taking into consideration that dorsal wrist ganglions predominated in the group of wrist ganglions (285 out of 394 cases; $72.34 \%$ ), while volar retinacular ganglions constituted the largest subgroup of hand ganglions (107 out of 126 cases; 84.92\%).

A comparison of age distribution between patients with dorsal wrist ganglions and those with volar retinacular ganglions revealed a statistically significant difference indicating a substantially higher age of the patients diagnosed with volar retinacular ganglions (Kruskal-Wallis test, $\mathrm{p}<0.001)$. For the above-mentioned reasons, this also had an effect on the higher age of the patients with hand ganglions when compared to those with wrist ganglions (median age 50.5 vs. 37 years; Mann-Whitney U test, $\mathrm{p}<0.001$ ), a result that also reached statistical significance. In summary, in the right upper limb (being the dominant limb in most of the patients), the preponderance of hand ganglions, mainly deriving from the flexor tendon sheath, was observed. Due to the higher mean age in this patient subgroup, joint overload could be taken into consideration as the underlying cause of ganglion formation. Such suggestions have been previously made by other authors. ${ }^{21}$ However, determining a direct connection between volar retinacular ganglion formation and the type of patient occupation or physical activity is very difficult. ${ }^{22}$

Ganglions of the hand and wrist constitute the group of tumors most commonly encountered in general practice. ${ }^{3}$ Establishing the diagnosis is relatively easy thanks to their certain characteristic features and specific location. ${ }^{1,3}$

Paradoxically, our knowledge on the pathomechanisms underlying formation and further growth of ganglions is still very limited. At least several theories aimed at ex- plaining ganglion pathophysiology exist but all of them have certain weaknesses. ${ }^{12,15,23-26}$

The first of these theories suggests that a ganglion is a herniation of the joint capsule (herniation of the synovial tissue from the joint). According to this concept, the fluid filling the cyst would originate from the joint and would be pumped into the cyst through a one-way valve mechanism. ${ }^{15,25,27}$ The weakness of this theory is the lack of synovial lining within the cyst. It is also worth noting that the cystic fluid differs in thickness and chemical composition from intra-articular synovial fluid. ${ }^{27}$

The second, "capsular rent" theory says that injuries to the joint lead to its damage, therefore enabling the leakage of synovial fluid into the periarticular tissue. Watson et al., in their study published in 1989, suggested that "the ganglion is a secondary manifestation of an underlying periscaphoid ligament injury". ${ }^{28}$ McKeon et al., having prospectively analyzed a group of 96 patients with symptomatic dorsal wrist ganglions and compared them with 96 age- and sex-matched healthy individuals in a control group, proved that the subjects with symptomatic ganglions demonstrated significantly increased rates of generalized ligamentous hyperlaxity. In the opinion of the authors, this should not be treated as a direct cause and effect relationship, but may indicate the possibility of the same underlying pathological entity causing both. ${ }^{18}$ Osterman and Raphael demonstrated that the majority of arthroscopically-treated dorsal wrist ganglions were found in patients with concomitant scapholunate and lunotriquetral ligamentous injury. The authors concluded that: "increased intercarpal laxity may contribute to ganglion cyst formation". ${ }^{29}$ Povlsen and Peckett expressed a similar opinion that a ganglion is a result of underlying scapholunate pathology or instability. ${ }^{30}$

Rizzo et al. reported contradictory findings regarding this issue. The authors found no cases of scapholunate ligament instability among 41 patients treated arthroscopically for dorsal wrist ganglions. ${ }^{11}$ Similarly, in the material published by Lowden et al., the majority of wrist ganglions detected on MRI examination were not accompanied by ligamentous disruption or soft tissue oedema. ${ }^{23}$

The assumption that ligamentous pathology is the cause of ganglion formation is controversial. Taking into consideration the total incidence of all ganglions - those treated surgically, with aspiration or observation as well as undiagnosed, asymptomatic lesions, we would need to assume that ligamentous hyperlaxity of the wrist is a common condition. If it was a systemic problem, ganglions should develop as multiple lesions, on both sides of the body. It is also difficult to explain the fact that a high percentage of ganglions spontaneously resolve in long-term observation, although ligamentous hyperlaxity, allegedly underlying their formation, persists. ${ }^{24}$ Furthermore, no explanation exists as to why ganglions develop mainly in young individuals. Wrist ganglions prevail in clinical practice. In our study, they affected 
younger patients and were found more often in the nondominant limb.

The third theory proposes that an extra-articular degenerative process (mucoid degeneration) is the cause of both the formation of the cyst and its subsequent direct connection to the joint. ${ }^{15,25,27}$

Another theory claims that persistent joint irritation provokes mesenchymal cells to secrete mucin. Small pools of mucin join to create the main cyst, around which a pseudocapsule lacking synovial lining is formed. ${ }^{27}$

An MRI study of 103 volunteers conducted by Lowden et al. revealed the presence of 53 asymptomatic wrist ganglions, measuring averagely $8 \times 3 \mathrm{~mm}$. The length of the ganglions varied from 3 to $22 \mathrm{~mm}$ and their width from 2 to $10 \mathrm{~mm}$. Seventy percent of the detected ganglions were located on the volar side of the wrist. ${ }^{23}$ This study provides evidence that ganglions can also be found in asymptomatic patients. Consequently, the incidence of ganglions in the general population is higher than calculated on the basis of the analysis of available clinical data on patients treated for symptomatic cysts.

Gant et al. stated: "the fact that wrist ganglions are present in a large percentage of asymptomatic individuals makes it clear that we do not understand the relationship between a ganglion cyst (pathophysiology) and illness behaviour (eg. pain and disability)".24

The strengths of our research is the large number of cases included in the study as well as comprehensive and multidirectional statistical analysis of the gathered material. The retrospective character of the study and homogeneity of the patient group, e.g. with respect to the treatment method used, can be considered its major weaknesses.

\section{Conclusion}

The results of the statistical analysis conducted were consistent with findings reported by other authors, with respect to patient age, gender and ganglion location. In our study, ganglions affected females 2.8 times more often than males and were evenly distributed between the left and right side of the body. Wrist ganglions predominated over hand ganglions (76 vs. 24\%, respectively). Wrist ganglions were found in younger and hand ganglions in older patients, with statistical significance.

It can be stated that no generally accepted theory capable of explaining all aspects of ganglion cyst formation and further course of the condition is available. Although the diagnosis and successful treatment of ganglions of the hand and wrist is possible and relatively uncomplicated, the pathophysiological mechanisms underlying ganglion cyst formation are still waiting to be thoroughly understood and explained.

\section{References}

1. Angelides AC, Wallace PF. The dorsal ganglion of the wrist: Its pathogenesis, gross and microscopic anatomy, and surgical treatment. J Hand Surg Am. 1976;1:228-235.

2. Clay NR, Clement DA. The treatment of dorsal wrist ganglia by radical excision. J Hand Surg Br. 1988;13:187-191.

3. Burke FD, Melikyan EY, Bradley MJ, Dias JJ. Primary care referral protocol for wrist ganglia. Postgrad Med J. 2003;79:329-331.

4. Barnes WE, Larsen RD, Posch JL. Review of ganglia of the hand and wrist with analysis of surgical treatment. Plast Reconstr Surg. 1964;34:570-578.

5. Stephen AB, Lyons AR, Davis TR. A prospective study of two conservative treatments for ganglia of the wrist. J Hand Surg Br. 1999;24:104-105.

6. Aydin A, Kabakaş F, Erer M, Ozkan T, Tunçer S. Surgical treatment of volar wrist ganglia. Acta Orthop Traumatol Turc. 2003;37:309-312.

7. Abe $\mathrm{Y}$, Watson HK, Renaud S. Flexor tendon sheath ganglion: Analysis of 128 cases. Hand Surg. 2004, 9, 1-4.

8. [8] Gang RK, Makhlouf S. Treatment of ganglia by a thread technique. J Hand Surg Br 1988;13:184-186.

9. Singhal R, Angmo N, Gupta S, Kumar V, Mehtani A. Ganglion cysts of the wris: A prospective study of a simple outpatient management. Acta Orthop Belg. 2005;71:528-534.

10. Dermon A, Kapetanakis S, Fiska A, Alpantaki K, Kazakos K. Ganglionectomy without repairing the bursal defect: Long-term results in a series of 124 wrist ganglia. Clin Orthop Surg. 2011;3:152-156.

11. Rizzo M, Berger RA, Steinmann SP, Bishop AT. Arthroscopic resection in the management of dorsal wrist ganglions: Results with a minimum 2-year follow-up period. J Hand Surg Am. 2004;29:59-62.

12. Shoaib A, Clay NR. Ganglions. Curr Orthop. 2002;16:451-461.

13. Craik JD, Walsh SP. Patient outcomes following wrist ganglion excision surgery. J Hand Surg Eur Vol. 2012;37:673-677.

14. Lidder S, Ranawat V, Ahrens P. Surgical excision of wrist ganglia; literature review and nine-year retrospective study of recurrence and patient satisfaction. Orthop Rev (Pavia). 2009;1:e5.

15. Dias JJ, Dhukaram V, Kumar P. The natural history of untreated dorsal wrist ganglia and patient reported outcome 6 years after intervention. J Hand Surg Eur Vol. 2007;32:502-508.

16. Teefey SA, Dahiya N, Middleton WD, Gelberman RH, Boyer MI. Ganglia of the hand and wrist: A sonographic analysis. AJR Am J Roentgenol. 2008;191:716-720.

17. Jebson PJ, Spencer EE Jr. Flexor tendon sheath ganglions: Results of surgical excision. Hand (NY). 2007;2:94-100.

18. McKeon KE, London DA, Osei DA, et al. Ligamentous hyperlaxity and dorsal wrist ganglions. J Hand Surg Am. 2013;38:2138-2143.

19. Rollins KE, Ollivere BJ, Johnston P. Predicting successful outcomes of wrist and finger ganglia. Hand Surg. 2013;18:41-44.

20. Westbrook AP, Stephen AB, Oni J, Davis TR. Ganglia: The patient's perception. J Hand Surg Br. 2000;25:566-567.

21. Matthews P. Ganglia of the flexor tendon sheaths in the hand. J Bone Joint Surg Br. 1973;55:612-617.

22. Al-Khawashki H, Hooper G. The distribution of fibrous flexor sheath ganglions. J Hand Surg Br. 1997;22:226-227.

23. Lowden CM, Attiah M, Garvin G, Macdermid JC, Osman S, Faber KJ. The prevalence of wrist ganglia in an asymptomatic population: Magnetic resonance evaluation. J Hand Surg Br. 2005;30:302-306.

24. Gant J, Ruff M, Janz BA. Wrist ganglions. J Hand Surg Am. 2011; 36:510-512.

25. Minotti P, Taras JS. Ganglion cysts of the wrist. J Hand Surg Am. 2002;2:102-107.

26. Finsen V, Håberg O, Borchgrevink GE. Surgery for ganglia of the flexor tendon sheath. Orthop Rev (Pavia). 2013;5:e6.

27. Gude W, Morelli V. Ganglion cysts of the wrist: Pathophysiology, clinical picture, and management. Curr Rev Musculoskelet Med. 2008;1:205-211.

28. Watson HK, Rogers WD, Ashmead D $4^{\text {th }}$. Reevaluation of the cause of the wrist ganglion. J Hand Surg Am. 1989;14:812-817.

29. Osterman AL, Raphael J. Arthroscopic resection of dorsal ganglion of the wrist. Hand Clin. 1995;11:7-12.

30. Povlsen B, Peckett WR. Arthroscopic findings in patients with painful wrist ganglia. Scand J Plast Reconstr Surg Hand Surg. 2001;35:323-328. 